\section{Take direct action on climate inaction}

We are scientists recently arrested in Canada for

blockading a 125-car train carrying coal destined to release 26,000 tonnes of carbon dioxide into the atmosphere. We joined 11 other Canadians in this act, despite the personal risks and potential negative impact on our careers.

Time is running short and our dialogues on climate change with Canada's conservative government have been futile, which is why we undertook this extreme action. We were following the example of NASA climatologist James Hansen, who has been arrested three times in the past three years for civil disobedience in protesting against the mining of coal or development of the Canadian oil sands.

If the rate of carbon emissions does not decrease soon, the $2{ }^{\circ} \mathrm{C}$ threshold for serious consequences of climate change could be broken this century (M. New et al. Phil. Trans. R. Soc. A 369, 6-19; 2011). Yet many nations, including Canada and the United States, remain more concerned with building infrastructure to extract and transport fossil fuels than with seeking alternative energy solutions.

Civil disobedience has a long-standing tradition of inducing social change when those in power fail to act. Governments are neglecting their responsibility to future generations. Because science is built on professionalism and objective evidence, media coverage of our arrests will ensure that they, and the voting public, receive a forceful message.

Alejandro Frid West Vancouver, British Columbia, Canada. alejfrid@gmail.com Lynne Quarmby Simon Fraser University, Burnaby, British Columbia, Canada.

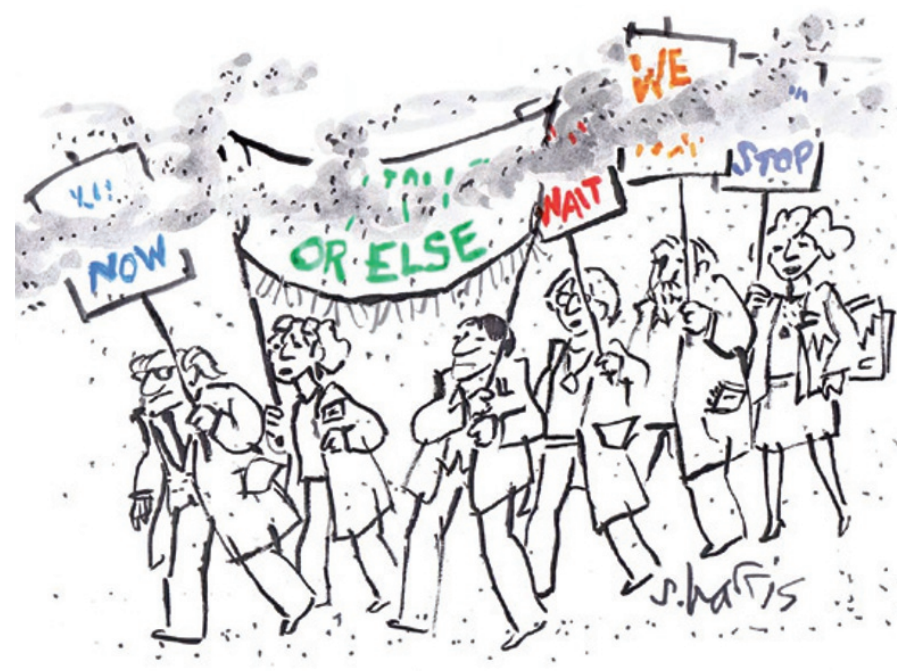

and important research institutes have laid off many highly qualified scientists. Even the Ramón y Cajal programme for young researchers has failed to fulfil its contractual obligations, forcing an end to the careers of bright young scientists.

This all comes at a time when research and development offers Spain the only certain route of recovery from economic collapse.

Sergio P. Acebrón German

Cancer Research Center,

Heidelberg, Germany.

s.perezacebron@dkfz-heidelberg.de

\section{Doubt in Australia's emissions scheme}

Policy uncertainty is dogging emissions-trading schemes. On 1 July, Australia introduced the largest carbon-pricing scheme outside the European Union, with a higher price for carbon permits than in the EU carbon market (F. Jotzo Nature Clim. Change 2, 475-476; 2012).

When we surveyed a sample of Australian large emitters, carbon financiers and carbonmarket experts (see go.nature. com/jlehiy), we found that $79 \%$ think there will still be a carbon price in 2020. But 38\% expect that the current scheme will be repealed by the end of 2015 , in line with the opposition's pledge. Of those who expect repeal, half think that a carbon price will be reinstated in Australia by 2020 .

According to our survey, the average expected carbon price for the first three years of Australia's scheme is predicted to start near the 'fixed' (legislated) price of Aus $\$ 23$ per tonne of carbon dioxide equivalent. It then falls to an expected Aus $\$ 11$ per tonne for 2016 before rising to Aus $\$ 22$ per tonne in 2025.

Assessments of future prices vary greatly between experts, indicating pervasive uncertainty. Low-carbon investments depend on expectations about future prices, and can be hampered by too much uncertainty. Managing prices in emissions-trading schemes could help. One way would be to use a fixed price, as in Australia, or a price band. Another would be to vary the supply of permits, as proposed for the EU carbon market, in which prices have dropped following economic troubles.

Setting carbon prices in line with domestic policy ambitions may be an attractive option for other countries, including for China's planned emissionstrading schemes. It will not alleviate policy uncertainty, but it can reassure businesses that lowcarbon investments will pay off financially and make revenues more predictable.

Frank Jotzo Australian National University, Canberra, Australia. frank.jotzo@anu.edu.au

\section{Spanish cuts: careers come to abrupt end}

Carmen Vela suggests that the $22.5 \%$ cut to the already limited Spanish science budget is an opportunity for improvement (Nature 486, 7; 2012). But her optimism is unrealistic.

Spain already has substantially fewer researchers per capita than other members of the European Union such as France or Germany. Entire grant programmes have disappeared

\section{Spanish cuts: more economic damage}

The Spanish government's secretary for research, development and innovation has attempted to put a positive spin on the country's severe shortfall in research funding (C. Vela Nature 486, 7; 2012). But the latest drop in funds is unlikely to make the little science that remains more competitive.

Returns from investment in science are unpredictable. But limited funding will mean that high-risk projects get left out and that scientists will be driven abroad or choose alternative careers. Investment during the bonanza years will have served no purpose.

These deep cuts for science will deprive the Spanish economy as a whole. Creating an environment that is conducive to research and innovation calls for a long and sustained input from government, irrespective of economic cycles.

Manuel Corpas The Genome Analysis Centre, Norwich, UK. manuel.corpas@tgac.ac.uk

\section{Spanish cuts: reform bureaucratic culture}

The Spanish government's draconian cuts to its science budget do indeed present us with an opportunity (C. Vela 